\title{
ANALISIS INSTRUMEN KEBIJAKAN FISKAL TERHADAP PERTUMBUHAN EKONOMI DI 35 KABUPATEN / KOTA PROVINSI JAWA TENGAH TAHUN $2013-2017$
}

\author{
ANALYSIS INSTRUMENT OF A FISCAL POLICY TO ECONOMIC GROWTH IN 35 \\ CITIES PROVINCE CENTRAL JAVA IN 2013 - 2017
}

\author{
Fitri Bahari \& Nugroho SBM \\ Mahasiswa Magister Ilmu Ekonomi Dan Studi Pembangunan Fakultas Ekonomika Dan \\ Bisnis Universitas Diponegoro \\ Corresponding author: Nugroho SBM; Email: nugrohosbm@lecture.undip.ac.id; \\ nugroho.sbm@gmail.com; fitri.bahari17@gmail.com \\ Diterima: 27 Mei 2019, Direvisi: 8 Juli 2019, Disetujui: 12 Juli 2019
}

\begin{abstract}
ABSTRAK
Penelitian ini bertujuan untuk menganalisis pengaruh pajak, belanja pegawai, belanja barang dan jasa, belanja tidak langsung terhadap pertumbuhan ekonomi di 35 Kabupaten/ Kota Provinsi Jawa Tengah pada tahun 2013-2017, sebagai akibat pengambilan kebijakan fiskal. Data yang digunakan dalam penelitian ini adalah data panel (data time series selama lima tahun dari 2013-2017, dan data cross-section sebanyak 35 data yang mewakili Kabupaten/ Kota Di Provinsi Jawa Tengah). Metode analisis penelitian ini mengunakan regresi data panel fixed effect model. Analisis regresi data panel digunakan untuk mengetahui pengaruh variabel-variabel independen terhadap pertumbuhan ekonomi. Hasil estimasi dalam penelitian ini menunjukan bahwa variabel belanja tidak langsung berpengaruh positif dan signifikan terhadap pertumbuhan ekonomi, variabel pajak, belanja pegawai berpengaruh negatif dan signifikan terhadap pertumbuhan, sedangkan variabel belanja barang dan jasa tidak berpengaruh terhadap pertumbuhan ekonomi. Dapat disimpulkan bahwa variabel belanja lagsung, pajak, dan belanja pegawai memiliki pengaruh terhadap pertumbuhan ekonomi sebagai dampak pengambilan kebijakan fiskal. Namun variabel belanja barang dan jasa tidak memiliki pengaruh terhadap pertumbuhan ekonomi di Kabupaten/ Kota Provinsi Jawa Tengah. Berdasarkan hasil penelitian diperlukan efektifitas alokasi anggaran belanja maupun penerimaan pemerintah, agar lebih dapat merespon kebijakan fiskal regional yang diambil pemerintah.
\end{abstract}

Kata kunci: kebijakan fiskal, pertumbuhan ekonomi, pengeluaran pemerintah, pajak.

\begin{abstract}
This study examines the role of fiscal policy in the economic growth in 35 Cities/Regency in Central Java Province in 2013 - 2017. This study using panel data with fixed effect model analysis to explain determinants of economic growth. The result of this study show that determinants of economic growth indicate that tax and personnel expenditure have a negative effect to economic growth. While indirect expenditure has a positive influence on economic growth. The results also suggest that goods and services expenditure have an unsignificant influence on economic growth 35 Cities in Province Central Java.
\end{abstract}

Keywords: fiscal policy, economic growth, government expenditure, tax.

Analisis Instrumen Kebijakan Fiskal Terhadap Pertumbuhan Ekonomi di 35 Kabupaten/Kota Provinsi Jawa 
PENDAHULUAN

Keberhasilan pembangunan ekonomi suatu negara dapat dilihat dari tingkat taraf hidup masyarakat yang meliputi pendapatan perkapita, pendidikan, inflasi yang terkendali, kesehatan, kesempatan kerja dan lainnya. Menurut Licolin (2004) pembangunan ekonomi merupakan proses yang berkaitan antara faktor-faktor yang dapat menghasilkan pembangunan ekonomi yang dapat dianalisis dan dilihat baik secara nasional maupun regional. Pembangunan ekonomi tidak lepas kaitannya dengan pertumbuhan ekonomi. Pertumbuhan ekonomi sendiri juga dapat dilihat sebagai salah satu alat ukur keberhasilan dalam proses pembangunan, hal ini dapat dilihat dari tingkat perkembangan PDRBdi negara tersebut. $\begin{array}{lrr}\begin{array}{c}\text { Selama } \\ \text { pertumbuhan }\end{array} & \begin{array}{r}\text { periode } \\ \text { ekonomi }\end{array} & \text { Indonesia }\end{array}$ mengalami fluktuasi. Dari seluruh pulau yang ada di Indonesia. Jika dilihat dari data Badan Pusat Statistika Pulau Jawa merupakan sumbasi terbesar dalam Distribusi PDRB di Indonesia. Pada tahun 2013 distribusi PDRB Di Pulau Jawa sebesar 57, pada tahun 2013 sebesar 57,06 persen meningkat menjadi 58,33 persen pada tahun 2015, dan meningkat lagi di tahun 2017 menjadi sebesar 58,49 persen. jika dilihat dari distribusi PDRB tiap provinsi yang ada, Jawa Tengah termasuk dalam daftar sepuluh provinsi yang memiliki distribusi yang besar terhadap PDRB nasional.. Hal tersebut dapat dilihat dalam tabel 1 laju pertumbuhan ekonomi di Provinsi Jawa Tengah

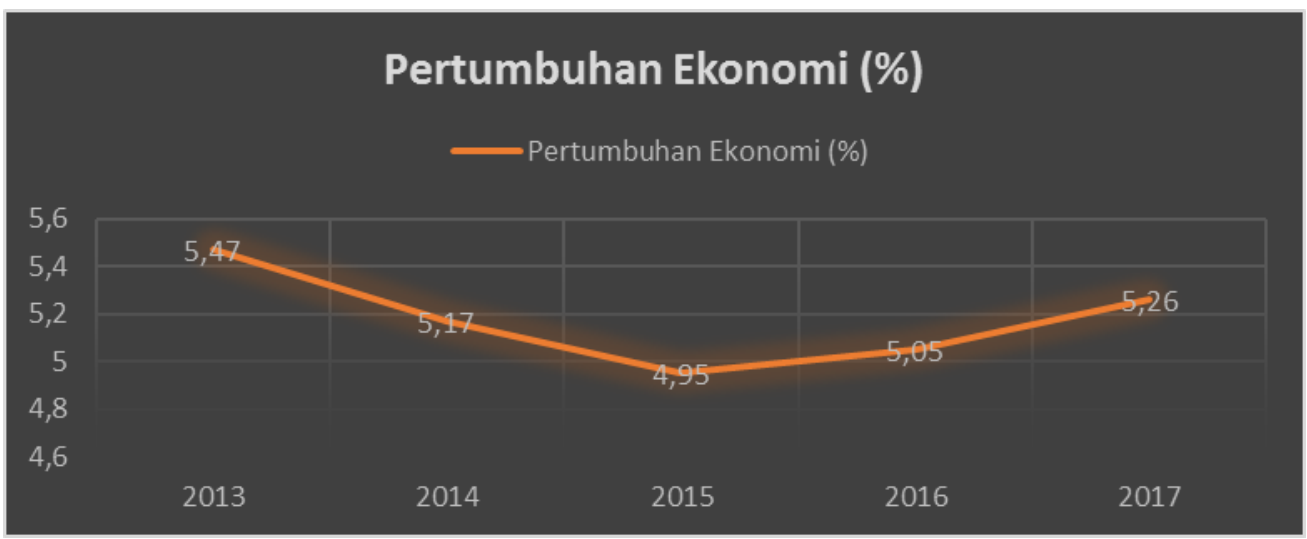

Gambar 1

Laju Pertumbuhan Ekonomi Provinsi Jawa Tengah 2013-2017 Sumber: BPS 2018, diolah.

Berdasarkan Gambar 1 dapat dilihat bahwa pertumbuhan ekonomi di Jawa Tengah mengalami fluktuasi, pada tahun 2013 pertumbuhan ekonomi sebesar 5,47 persen turun menjadi 4,95 persen di tahun 2015, dan meningkat menjadi sebesar 5.26 persen di tahun 2017.

Salah satu upaya pemerintah dalam mendorong peningkatan partumbuhan ekonomi di Provinsi Jawa adalah dengan pengambilan kebijakan fiskal dan moneter. Kebijakan fiskal pada dasarnya alat atau instrumen pemerintah yang sangat penting peranannya dalam sistem perekonomian. Instrumen fiskal itu berguna untuk mendorong pertumbuhan ekonomi, menjaga stabilitas harga atau mengendalikan inflasi, memperluas basis kegiatan ekonomi berbagai sektor, dan 
secara khusus memperluas lapangan usaha untuk menurunkan tingkat pengangguran.

Kebijakan fiskal memiliki dua instrumen dalam kebijakanya yaitu melalui pos pendapatan atau melalui pos pengeluaran (Budiono, 1995). Jika dilihat dari sisi pendapatan dapat berupa penerimaan pajak, pinjaman dalam negeri, pinjaman luar negeri, dan pinjaman dari Bank Sentral. Sedangkan jika dilihat dari pos pengeluaran dapat berupa pembelian barang dan jasa, belanja pegawai, dan transfer payments.

Tujuan utama dari kebijakan fiskal salah satunya adalah stabilitas ekonomi baik jangka pendek maupun dalam jangka panjang. Dalam kebijakan fiskal stabilisasi ekonomi diusahakan dengan melakukan penyesuain baik dari belanja negara ataupun pajak yang meru- pakan salah satu bentuk respon dari adanya output gap dalam suatu perekonomian. Apabila perekonomian berada pada posisi dibawah tingkat ekuilibriumnya atau yang sering disebut terjadinya resesi. Langkah yang akan di ambil oleh pemerintah salah satunya dengan menetapkan kebijakan fiskal dengan meningkatkan pengeluaran atau menurunkan tingkat penerimaan pajak. Sebaliknya apabila terjadi ekspansi ekonomi atau dimana perekonomian berada dalam posisi diatas tingkat ekuilibriumnya, pemerintah akan mengambil langkah kebijakan dengan meningkatkan penerimaan pajak atau dengan mengurangi pengeluaran belanja pemerintah. Hal tersebut diharapkan perekonomian akan kembali pada tingkat ekuilibriumnya.

Tabel 1

Indikator Ekonomi Provinsi Jawa Tengah 2012-2017 (Juta Rupiah)

\begin{tabular}{|c|c|c|c|c|}
\hline Tahun & Pajak & $\begin{array}{c}\text { Belanja Barang } \\
\text { dan Jasa }\end{array}$ & $\begin{array}{c}\text { Belanja } \\
\text { Pegawai }\end{array}$ & $\begin{array}{c}\text { Belanja Tidak } \\
\text { Langsung }\end{array}$ \\
\hline 2012 & 5.590597 & 1.977 .572 & 1.241 .601 & 8.540 .013 \\
\hline 2013 & 6.716 .170 & 2.143 .192 & 1.368 .517 & 9.213 .697 \\
\hline 2014 & 8.213 .118 & 2.397 .686 & 1.887 .758 & 10.808 .021 \\
\hline 2015 & 9.090 .677 & 2.615 .823 & 2.186 .704 & 12.396 .064 \\
\hline 2016 & 9.672 .518 & 2.493 .432 & 2.239 .684 & 13.717 .073 \\
\hline 2017 & 10.572 .698 & 3.381 .260 & 6.092 .077 & 18.648 .854 \\
\hline
\end{tabular}

Sumber: BPS 2018, diolah.

Berdasarkan data dari Tabel 1 dapat dilihat penerimaan pajak daerah Provinsi Jawa Tengah tahun 2012-2017 mengalami peningkatan. Peningkatan penerimaan pajak salah satunya disebabkan oleh adanya pencanangan program pemerintah yaitu tax amnesti. Penerimaan pajak daerah meningkat dari 5.590.597 (juta) di tahun 2012, menjadi 10.572.698 (juta) di tahun 2017. Sedangkan jika dilihat dari total pengeluaran pemerintah belanja barang dan jasa tahun 2012-2017 mengalami fluktuasi, dimana pada tahun
2014 pengeluaran pemerintah untuk belanja barang dan jasa tahun 2014 sebesar 2.397.686 (juta), di tahun 2015 meningkat sebesar 2.514.682 (juta), dan menurun menjadi 2.493 .432 (juta) di tahun 2016.

Belanja Pegawai mengalami peningkatan setiap tahunnya jika dilihat dari data 2012-2017. Peningkatan belaja pegawai dari 1.241.601 (juta) di tahun 2012, meningkat menjadi 2.186.704 (juta) di tahun 2015, dan meningkat kembali menjadi 6.092.077 (juta) pada tahun 2017 . 
Sedangkan Belanja tidak Langsung Provinsi Jawa Tengah tahun 2012-2017 juga terus mengalami peningkatan. Pada tahun 2012 sebesar 8.540.013 (juta), meningkat menjadi 12.396.064 (juta) di tahun 2015, dan meningkat kembali pada tahun 2017 sebesar 18.648.854 (juta).

Hasil penelitian yang dilakukan oleh Mehrotra (2018), yang menekankan tentang efektifitas stabilisasi kebijakan fiskal melalui belanja atau pemasukan pemerintah dimana diketahui bahwa kebijakan fiskal melalui pemasukan dan belanja pemerintah sama-sama memberikan dampak, tetapi instrumen belanja pemerintah lebih efektif dalam merespon kebijakan fiskal yang diambil. Dengan melihat gambaran kondisi tersebut setelah pengambilan kebijakan fiskal dapat diketahui bahwa daerah belum mampu meningkatkan pertumbuhan ekonomi secara signifikan serta masih adanya kesenjangan antar daerah Kabupaten/Kota di Provinsi Jawa Tengah. Penelitian ini menganalisis pengaruh variabel pajak, belanja barang dan jasa, belanja pegawai, dan belanja tidak langsung terhadap pertumbuhan ekonomi di 35 Kabupaten/ Kota Provinsi Jawa Tengah pada tahun 2013-2017 sebagai akibat kebijakan fiskal yang diambil oleh pemerintah daerah.

\section{METODE PENELITIAN}

Penelitian ini dilakukan di 35 Kabupaten/ Kota Provinsi Jawa Tengah dalam periode 2013 - 2017. Sumber data yang digunakan dalam penelitian ini berasal dari Direktorat Jenderal Perimbangan Keuangan dan Badan Pusat Statistik. Metode yang digunakan untuk menganalisis data dalam penelitian ini adalah mengunakan metode panel data. Teknik estimasi mengunakan unit data cross section dan time series. Alat analisis yang digunakan adalah Microsoft Excel 2016 software Eviews 10 untuk mengestimasi faktor-faktor determinan partumbuhan ekonomi mengunakan panel data.

Variabel dependen penelitian ini adalah laju pertumbuhan ekonomi. Sedangkan variable independenden dalam penelitian ini adalah Pajak, Belanja Pegawai, Belanja Barang dan Jasa, dan Belanja tidak Langsung.

Untuk mencapai hasil penelitian dan pengujian hipotesis dalam penelitian ini maka digunakan analisis regresi dengan metode GLS (Generalized Least Squares) (Gujarati, 2010). Penelitian ini mengunakan model data panel fixed effect model. Model ini, secara umum dapat ditunjukkan dengan formulasi sebagai berikut:

$$
\begin{aligned}
& Y_{i t}=\beta_{1}+\beta_{2} \ln \left(T_{j t}\right)+\beta_{3} \ln \left(B P_{j t}\right)+\beta_{4} \ln \left(G_{j t}\right)+\beta_{5} \ln \left(B T L_{j t}\right)+\varepsilon_{j t} \\
& \text { Dimana: } \\
& \mathrm{Y}=\text { pertumbuhan ekonomi } \\
& \mathrm{T} \quad=\text { pajak } \\
& \mathrm{BP}=\text { belanja pegawai } \\
& \text { BTL = belanja tidak langsung } \\
& \text { ejt } \quad=\text { random error }
\end{aligned}
$$

HASIL DAN PEMBAHASAN

\section{Hasil Estimasi}

Secara umum penelitian ini bertujuan untuk menganalisis pengaruh pajak, belanja barang dan jasa, belanja pegawai dan belaja tidak langsung di 35
Kabupaten/Kota Provinsi Jawa Tengah sebagai dampak pengambilan kebijakan fiskal. Hasil estimasivariabel independent terhadap pertumbuhan ekonomi terlihat pada Tabel 2 dibawah ini. 


\section{Tabel 2}

Hasil Estimasi Variabel Pertumbuhan Ekonomi Dengan Fixed Effect Model

\begin{tabular}{|c|c|c|}
\hline Variable & Koefisien & $\begin{array}{l}\text { t-ratio } \\
\text { (signif) }\end{array}$ \\
\hline konstanta & 4.884635 & $\begin{array}{l}3.204211 \\
(0.0017)\end{array}$ \\
\hline LnT & -0.058455 & $\begin{array}{c}-2.304153 \\
(0.0227)\end{array}$ \\
\hline $\operatorname{lnBP}$ & -0.173390 & $\begin{array}{c}-2.096190 \\
(0.0379)\end{array}$ \\
\hline $\ln G$ & -0.024805 & $\begin{array}{l}-1.139941 \\
(0.2563)\end{array}$ \\
\hline $\operatorname{lnBTL}$ & 0.131435 & $\begin{array}{c}2.376094 \\
(0.0189) \\
\end{array}$ \\
\hline R-square & \multicolumn{2}{|c|}{0.651033} \\
\hline F-ratio & \multicolumn{2}{|c|}{6.676879} \\
\hline (signif) & \multicolumn{2}{|c|}{$(0.000000)$} \\
\hline $\begin{array}{l}\text { Jumlah variabel signifikan } \\
\qquad \mathrm{N}\end{array}$ & \multicolumn{2}{|c|}{3 dari 4 variabel $(75 \%)$} \\
\hline Dw & \multicolumn{2}{|c|}{2.442727} \\
\hline
\end{tabular}

Sumber: data sekunder 2019, diolah.

Hasil estimasi menunjukan bahwa koefisien determinasi sebesar 65,10 persen variasi pertumbuhan ekonomi yang dijelaskan oleh variabel-variabel independennya (pajak, belanja pegawai, belanja barang dan jasa, dan belanja tidak langsung), sedangkan sisanya dijelaskan oleh variabel lain diluar model. Hasil ini juga diperkuat dengan probabilitas fstatistik dengan signifikasi 5 persen yaitu sebesar 0,000000. Artinya H0 ditolak dan H1 diterima menunjukan bahwa variabelvariabel independen secara bersama-sama berpengaruh terhadap variabel dependen.

Langkah selanjutnya melakukan pengujian deteksi penyimpangan asumsi klasik. Untuk uji normalitas dengan melihat nilai jarque bera sebesar 4,65279 dengan probabilitas 0,097647 lebih besar dari taraf nyata sebesar 5 persen, maka dapat di simpulkan bahwa data berdistribusi normal. Dalam model ini diberikan pendekatan General Least Square (Cross Section Weights) dan diberikan perlakuan Cross Section SUR
(PCSE) dan Standart Errors and Covariance. Sehingga asumsi heteroskedastisitas dan autokolerasi dapat diabaikan. Selanjutnya uji multikolineritas dilakukan dengan mengunakan auxiliary regression, diketahui bahwa nilai $R$ square untuk seluruh estimasi bila dibandingkan dengan nilai $R$-square fixed effect model (65,10 persen) memiliki nilai lebih kecil, sehingga terjadinya multikolineritas dapat diabaikan.

\section{Pembahasan}

Variabel pajak berpengaruh negatif dan signifikan pada taraf nyata sebesar 0,05 . Artinya penurunan pajak akan memingkatkan pertumbuhan ekonomi di 35 Kabupaten/ Kota Provinsi Jawa Tengah. Menurut Boediono (1995) kenaikan pajak akan menyebabkan pendapatan disposibel menurun, dan berakibat pada turunya pengeluaran konsumsi, selanjutnya penurunan konsumsi akan menyebabkan turunnya keseimbangan equilibrilium perekonomi- 
an. Turunnya keseimbangan equilibrium ini akan memberikan dampak multiplier efek terhadap perekonomian.

Temuan selanjutnya bahwa variabel belanja pegawai berpengaruh negatif dan signifikan pada taraf nyata sebesar 0,05. Hal tersebut menjelaskan bahwa peningkatan belanja pegawai akan menurukan pertumbuhan ekonomi Di 35 Kabupaten/ Kota Provinsi Jawa Tengah. Menurut Azwar (2016) pengeluaran pemerintah akan dapat berpengaruh langsung maupun tidak langsung terhadap berbagai sektor perekonomian yang bertujuan untuk meningkatkan pertumbuhan ekonomi. Aldof Wagner memperkenalkan tentang teori law of increasing state activity dimana kecenderungan peningkatan pengeluaran pemerintah akan meningkatkan aktivitas pemerintah dalam perekonomian (Mangkoesoebroto, 2002). Dalam penelitian ini pengeluaran pemerintah dalam belanja pegawai berpengaruh negatif terhadap pertumbuhan dimungkinkan karena adanya perbedaan dalam angaran belanja pegawai untuk setiap daerah, ada daerah yang memiliki kecenderungan meningkat setiap tahun dan ada pula daerah yang mengalami fluktuasi dalam periode penelitian.

$\begin{array}{rcc}\text { Belaja } & \text { Tidak } & \text { Langsung } \\ \text { berpengaruh } & \text { positif dan signifikan }\end{array}$ terhadap taraf nyata sebesar 0,05. Artinya bahwa peningkatan belanja tidak langsung akan menyebabkan peningkatan pertumbuhan ekonomi Di 35 Kabupaten/ Kota Provinsi Jawa Tengah. Secara teori, belanja tidak langsung berpengaruh terhadap pertumbuhan ekonomi melalui alokasi angaran yang efisien guna untuk meningkatkan kesejahteraan masyarakat. Peningkatan kesejahteraan masyarakat merupakan salah satu ukuran keberhasilan pembangunan ekonomi, artinya bahwa meningkatnya kesejahteraan ekonomi akan meningkatkan pertumbuhan ekonomi.

Berdasarkan temuan penelitian variabel belanja barang dan jasa berpengaruh negatif dan tidak signifikan terhadap pertumbuhan ekonomi Di 35 Kabupaten/ Kota Provinsi Jawa Tengah. Tidak signifikannya variabel belanja barang dan jasa mengindikasi bahwa barang dan jasa pada kenyataannya bukanlah faktor yang berpengaruh terhadap perubahan nilai pertumbuhan ekonomi di 35 Kabupaten/Kota di Jawa Tengah. Dalam pendekatan Keynes, kebijakan fiskal dapat menggerakkan perekonomian karena peningkatan pengeluaran pemerintah memiliki efek multiplier dengan cara menstimulasi tambahan permintaan untuk barang konsumsi rumah tangga. Menurut Boediono (1995) peningkatan belanja barang dan jasa pemerintah akan meningkatkan keseimbangan equilibrium perekonomian, selanjutnya perubahan keseimbangan ekuilibrium akan mengalami proses multiplier efek. Namun dalam penelitian ini belanja barang dan jasa tidak memiliki pengaruh terhadap pertumbuhan ekonomi di 35 Kabupaten/ Kota Provinsi Jawa Tengah. Hal tersebut dimungkinkan kebijakan fiskal yang diambil oleh pemerintah daerah belum mampu mendistribusikan pendapatan secara efisien sehingga tidak berdampak terhadap pertumbuhan ekonomi. Hal ini didukung oleh penelitian yang dilakukan oleh Ramayandi (2003) dimana adanya hubungan negative dan tidak signifikan barang dan jasa terhadap pertumbuhan ekonomi di dalam jangka panjang.

\section{KESIMPULAN DAN SARAN Kesimpulan}

Berdasarkan hasil penelitian dan pembahasan terkait pengaruh pajak, belanja pegawai, belanja barang dan jasa, dan belanja tidak langsung terhadap 
pertumbuhan ekonomi 35 Kabupaten/ Kota Di Provinsi Jawa Tengah sebagai dampak kebijakan fiskal yang diambil pemerintah dapat disimpulkan sebagai berikut: Pajak, dan belanja pegawai berpengaruh negatif dan signifikan terhadap pertumbuhan ekonomi Di 35 Kabupaten / Kota Provinsi Jawa Tengah. Belanja Tidak Langsung berpengaruh positif dan signifikan terhadap pertumbuhan ekonomi. Sedangkan Belanja Barang dan Jasa tidak berpengaruh terhadap pertumbuhan ekonomi Di 35 Kabupaten/ Kota Provinsi Jawa Tengah

\section{Saran}

Berdasarkan dari kesimpulan penelitian yang dihasilkan, terdapat kondisi-kondisi yang belum optimal dalam pertumbuhan ekonomi di 35 Kabupaten / Kota di Jawa Tengah sebagai dampak dari pengambilan kebijakan fiskal. Selanjutnya agar diperoleh hasil yang optimal guna mendukung perekonomian secara keseluruhan, maka ada upaya-upaya yang harus dilakukan oleh berbagai pihak terkait, diantaranya sebagai berikut: Dalam penelitian ini, terdeteksi faktorfaktor yang berpengaruh signifikan terhadap pertumbuhan ekonomi di 35 Kabupaten / Kota di Jawa Tengah. Untuk meningkatkan pertumbuhan ekonomi di 35 Kabupaten / Kota di Jawa Tengah untuk meningkatkan efektivitas alokasi anggaran belanja diperlukan peran serta pemerintah dalam mengatur, dan mengelola anggaran belanja agar dapat lebih efisien, tepat sasaran, sehingga dapat dirasakan dampak dalam pengambilan kebijakan fiskal yang ada di daerah agar dapat mendorong peninkatan pertumbuhan ekonomi. 
DAFTAR PUSTAKA

Arsyad, L. .2004. Ekonomi Pembangunan. Yogyakarta: UPP STIM YKPN.

Azwar. 2016. Allocative Role of Government Through

Procurement of Goods/ Services and Its Impact on Indonesian Economy. Jurnal Kajian Ekonomi \& Keuangan Vol. 20 No. 2.

Baltagi, B.H. 2005. "Econometric Analysis of Panel Data". John Wiley \& Sons, Ltd, England.

Badan Pusat Statistik. 2018. "Database". www.bps.go.id. (1 April 2019).

Boediono. 1995. Seri Sinopsis Pengantar Ilmu Ekonomi No. 2 Ekonomi Makro. Yogyakarta: BPFE Yogyakarta.

Direktorat Jendral Perimbangan Keuangan. 2019. http://www.djpk.depkeu.go.id. (1 April 2019).

Gujarati, Damodar dan Dawn C. Porter. 2010. Dasar-Daar Ekonometrika (Buku 1). (Terj.) Eugenia Mardanugraha, dkk. Jakarta: Salemba Empat.

Gujarati, Damodar dan Dawn C. Porter. 2012. Dasar-Daar Ekonometrika (Buku 2). (Terj.) Raden Carlos Mangunson. Jakarta: Salemba Empat.

Gujarati, Damodar. 2007. Dasar-Daar Ekonometrika II. (Terj.) Julius A. Mulyadi, dan Yelvi Andri. Jakarta: Penerbit Erlangga.

Makrifah, S. A. (2010). Analisis Pengelolaan Keuangan Daerah dan Dampaknya terhadap Pembangunan Ekonomi Provinsi Jawa Timur. Tesis, Institut Pertanian Bogor, Indonesia.
Mangkoesoebroto, Guritno. 2002. Ekonomi Publik. Yogyakarta: BPFE.

Mehrotra, Neil R. 2018. Fiscal Policy Stabilization: Purchases or Transfers. International Journal of Central Banking Vol.14 No.2.

Paseki, Meilen Greri, Amaran Naukoko, Patrick Wauran.2014. Pengaruh Dana Alokasi Umum Dan Belanja Langsung Terhadap Pertumbuhan Ekonomi Dan Dampaknya Terhadap Kemiskinan Di Kota Manado Tahun 2004-2012. Jurnal Berkala Ilmiah Efisiens, Volume 14 No.3

Ramayandi, Arief. (2003). Economic Growth and Government Size in Indonesia: Some Lessons for The Local Authorities Department of Economics. Working Paper in Economics and Development Studies No. 200302.

Sodik, Jamzani Dan Didi Nuryanin.2005. Investasi Dan Pertumbuhan Ekonomi Regional (Studi Kasus Pada 26 Propinsi Di Indonesia, Pra Dan Pasca Otonomi). Jurnal Ekonomi Pembangunan Upn "Veteran" Yogyakarta, Volume 10 Halaman 157-170.

Sukirno, Sadono. 2005. Makro Ekonomi Teori Pengantar .Raja Grafindo Perkasa: Jakarta.

Suryati, D. 2015. Pengaruh Belanja Daerah Berdasarkan Klasifikasi Ekonomi terhadap Pengentasan Kemiskinan dan Indeks Pembangunan Manusia di Kabupaten/Kota Provinsi Nusa Tenggara Barat Tahun 20072012. Media Bina Ilmiah, 9 (7), 20-27. 